\title{
Apparat zur elektrolytischen Bestimmung von Metallen.
} Von

\section{Dr. L. C. Levoir}

in $\mathrm{Delft}$.

Bei der Anordnung von Apparaten zur elektrolytischen Bestimmung von Metallen wird öfters nicht beachtet, dass eine regelmässige Mischung der ganzen Lösung eine Hauptbedingung für die vollständige Abscheidung der Metalle ist. Demgemäss glaubt man auch fehlerhafte Resultate mehr auf chemische als auf mechanische Ursachen zurückführen zu müssen.

Der in Fig. 5 abgebildete Apparat, dessen ich mich seit längerer Zeit mit gutem Erfolg bediene, gewährleistet eine ausgezeichnete Mischung der Lösung und eine vollständige Abscheidung des Metalles. Die zu elektrolysirende Flüssigkeit ist in der grossen Platinschale EFG enthalten, welche auf drei mit dem positiven Pole der Batterie verbundenen $\mathrm{Me}$ tallknöpfen ruht. In einem $\mathrm{Ab}$ stand von etwa $3 \mathrm{~cm}$ ist innerhalb der grösseren eine zweite kleinere Platinschale an drei Platindrähten aufgehängt. Diese Drähte sind an einem Häkchen von dickerem Platindraht befestigt, welches bei $\mathrm{D}$ in die Fig. 5.

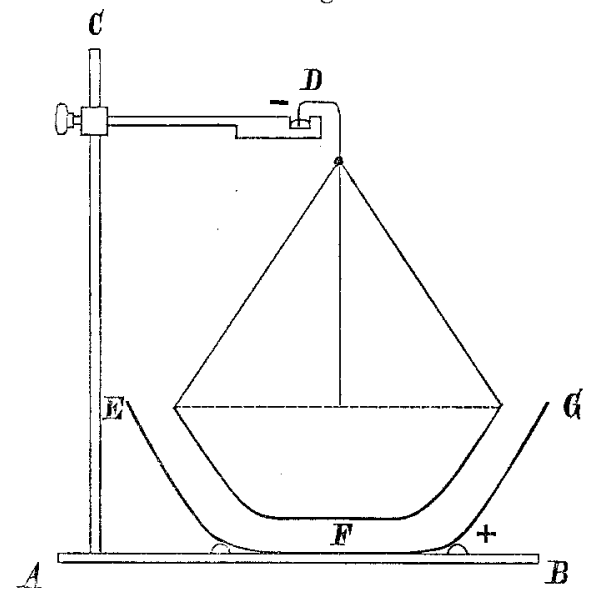
mit dem negativen Pol der Batterie verbundene Quecksilberfüllung einer Vertiefung in dem hölzernen Arm des Statives BACD taucht. Durch diese Art der Aufhängung erhält die negative Elektrode auf einfache Weise immer ihren richtigen Platz und wird eine zufällige Berührung der Elektroden unmöglich gemacht. Die zu elektrolysirende Lösung befindet sich zwischen den paralellen Wandungen der beiden Platinschalen. Die an den Wandungen der Schale E F G abgeschiedenen Sauerstoffbläschen steigen nach oben, bewirken so eine sehr gute Mischung der Flüssigkeit und bringen die ganze Lösung mit der negativen Elektrode in Berülrung, wodurch die Abscheidung des Metalles erleichtert und rascher vollendet wird. 